\title{
CONTRA LA ARROGANCIA DE CRITIAS : ¿PARMÉNIDES DETRÁS DEL CÁRMIDES?
}

\author{
AGAINST CRITIAS'ARROGANCE:
}

PARMENIDES BEHIND THE CHARMIDES ?

\author{
BEATRIZ BOSSI" \\ Universidad Complutense
}

\begin{abstract}
Resumen: En este trabajo me propongo mostrar que la tesis de Parménides 'no hay aprehensión de lo que no es' es el fundamento último de la refutación que construye Sócrates para descartar la definición de moderación que presenta Critias como 'ciencia de todas las ciencias y de sí misma’. A mi juicio, uno de los objetivos del diálogo es minar la arrogancia de Critias y mostrarle que no puede enseñar lo que es la moderación a su discípulo Cármides, porque carece de ella. Como resultado del proceso, se pone de manifiesto que la moderación no consiste en otra cosa que en la consciencia de los propios límites. Al final del diálogo, los interlocutores de Sócrates acaban en aporía pero de algún modo son redimidos por Platón en la acción dramática, al alcanzar, siquiera intencionalmente, una cierta consciencia de sus propios límites. Aunque carecen de una definición de moderación o sensatez, consiguen una cierta captación del significado de esta virtud en sus propias personas.
\end{abstract}

Palabras Clave: moderación, conocimiento, Parménides, ignorancia, arrogancia.

Aвstract: In this paper, I attempt to show how Socrates' argument is based on Parmenides' thesis that there is no grasp of what is not. The dialogue aims at refuting

*Universidad Complutense de Madrid, Facultad de Filosofía, 28040 Ciudad Universitaria Madrid; beabossi@filos.ucm.es 
Critias' definition of moderation as 'science of all sciences and of itself' in order to diminish his arrogance and to make him understand that he cannnot teach Charmides what moderation is, for he lacks this virtue. As a result of the process, moderation turns out to be a certain awareness of one's limits. At the end of the dialogue, Socrates's interlocutors end up in aporia but they are in a way redeemed by Plato as they reach, at least intentionally, a certain self-awareness of their own limits. Although they lack a definition of moderation, they have achieved a certain grasp of the meaning of this virtue in themselves.

KeYwords: moderation, knowledge, Parmenides, ignorance, arrogance

\section{Introducción}

En este trabajo me propongo mostrar cómo en el contexto del Cármides ${ }^{l}$ 'la gran aporía y extrañeza' de Sócrates (167 b-c ; 169 c) que aparentemente lo lleva a cuestionar la posibilidad del conocimiento del conocimiento y del conocimiento de la ignorancia no tiene otro objetivo que minar la arrogancia de Critias (e indirectamente, quizás, la de los sofistas de todos los tiempos). Contra lo que pudiera parecer, el diálogo afirma la posibilidad del conocimiento de uno mismo, del examen de lo que uno sabe y de lo que ignora y de lo que otros saben o ignoran. Esta afirmación se realiza siguiendo dos estrategias. Por una parte, el simple hecho de que Sócrates manifiesta en la acción dramática su consciencia de ignorancia, su situación aporética y su temor de creer saber lo que no sabe, dan fe de la posibilidad de un saber del no saber. Estamos ante una prueba fáctica, si no fuera posible llegar a saber que uno no sabe lo que creía saber, el temor de Sócrates no podría disiparse jamás y carecería de sentido. Por otra parte, en el plano teórico, Sócrates apela a lo que el logos permite o prohíbe. Al final del diálogo (175 b-c) Platón parece apoyarse en la autoridad de Parménides para desenmascarar a Critias. No es posible un saber de la ignorancia propia ni ajena si ese saber no hace referencia a un contenido de algún modo, porque el saber, el captar, el pensar están referidos necesariamente a lo que es. Y sin lo que es, no hay saber ni captación, ya que 'lo mismo es el ser y el captar' o 'lo mismo hay

${ }^{1}$ En el diálogo que lleva su nombre, Cármides, tío de Platón, es presentado como un bello adolescente que conversa con Sócrates en el -432, cuando éste acaba de llegar de la batalla de Potidea, comienzo de la guerra del Peloponeso. El otro interlocutor es Critias, primo de la madre de Platón. Ambos pertenecen a familias nobles. 
para el ser y el captar' según reza el enigmático Fragmento 3 de Parménides. El único objeto posible de conocimiento es lo real.

El pretendido 'saber del saber' que Critias se apresura a defender como definición de moderación es, por una parte, la antítesis de esta virtud y por la otra, tras el examen socrático, resultará imposible porque contradice al logos, i.e. al pensar y al lenguaje. El pensar vacío no es pensar, como dirá Platón en el Sofista. En su arrogancia, Critias se postula como poseedor de un saber que sólo sabe que sabe pero su posición no resiste el análisis de Sócrates y acaba por desvanecerse como una sombra insustancial.

Sin embargo, al final del diálogo Platón permite que la refutación dé su fruto y que los interlocutores de Sócrates se pongan en situación de adoptar una actitud nueva y contrastante con sus postulaciones anteriores. Recién al término del diálogo aparece en ellos una cierta moderación como conciencia de los propios límites. Se abre entonces un nuevo comienzo. La posibilidad de curación del joven Cármides se funda en dos asentimientos : el de Sócrates que acepta educarlo en el futuro y el de Critias, presumiblemente conciente de su fracaso, quien concede traspasarle a su discípulo.

\section{El método de abordaje y el tema del diálogo}

Una de las dificultades de los diálogos platónicos es su aparente carencia de unidad. Y en el caso de los diálogos de juventud, puede acentuarse la impresión de estar delante de una serie de temas inconexos que se degranan sucesivamente para finalizar en aporía, sin ofrecer una definición de lo que se busca. Sin embargo, en la mayoría de los casos, sólo en apariencia el diálogo nos deja con las manos vacías. Con el correr del discurso se van sembrando una serie de pistas que nos llevarían a casa si nos tomásemos el trabajo de desandar la lectura para recogerlas. Platón valora la capacidad del lector para resolver los enigmas que presenta. Por eso lo invita a participar, lo incluye en 'sus juegos de roles', lo desafía a buscar con él, y le provoca una frustración y un vacío para que se involucre personalmente. Los diálogos de Platón se deberían leer como enigmas a descifrar o como acertijos y no como doctrinas a memorizar.

El tema del Cármides es la $\sigma \omega \varphi \rho o \sigma v ́ v \eta$, que suele traducirse como 'moderación', 'auto-control' o 'sensatez'. Se trata de una virtud aristocrática por excelencia 
que supone sentido de la dignidad y el autodominio. En la época en que Platón escribe, Cármides y Critias, los interlocutores de Sócrates, eran famosos por haber sido miembros del régimen de los Treinta Tiranos, ricos antidemócratas nombrados por el rey de Esparta en - 404 tras la derrota de Atenas. Liderados por Critias, impusieron el terror contra sus enemigos políticos. Ambos murieron en el -403 en la lucha que restauró la democracia. Aunque probablemente se viesen a sí mismos como ejemplos de sensatez y dignidad aristocráticas, es posible que fueran la antítesis de esta virtud. Platón desea poner en evidencia sus contradicciones teóricas y prácticas y probablemente desvincular a Sócrates de toda responsabilidad en relación con sus actuaciones políticas. Los argumentos para refutarlos son, en el diálogo con Cármides, directos y simples y en el diálogo con Critias, indirectos y sutiles, al punto que el propio lector puede llegar a creer que el diálogo termina en aporía.

\section{La relación entre $\sigma \omega \varphi \rho \sigma^{\prime} \eta$ y sabiduría en ciertos diálogos platónicos}

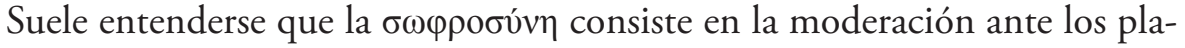
ceres. Así la define Platón en el Banquete (196 c). Sin embargo, en los distintos diálogos que escribe a lo largo de su vida, Platón no reduce esta virtud a la puesta en marcha de una cierta conducta recta frente a los placeres, sino que su perspectiva es mucho más profunda: toda virtud auténtica es sabiduría o va unida a la sabiduría. En otra parte ${ }^{2}$, he intentado defender que esta tesis se sostiene en la obra de Platón, al menos desde el Protágoras hasta el Político.

En el Protágoras Platón concibe 'las virtudes' como nombres que designan

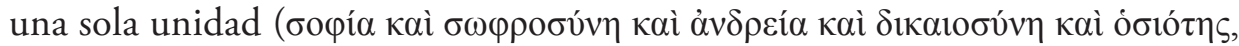

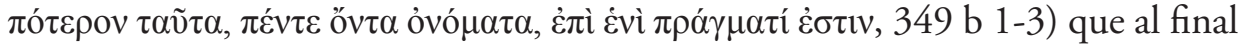
del diálogo es identificada como la sabiduría o el arte de medir. En el Banquete, toda virtud genuina deriva de la visión de la Forma de la Belleza (212 a). En el

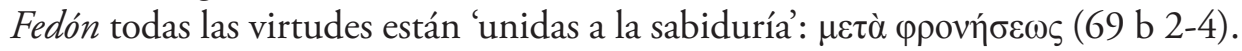

\footnotetext{
${ }^{2}$ Bossi (2016) 'Is the Thesis of the Implication of the Virtues abandoned in the Politicus?' Comunicación presentada en el II International Plato Spring Seminar (Madrid, 25-26 April 2016) en proceso de evaluación.
} 
Sin embargo, la peculiar relación entre la moderación y la sabiduría se expresa en distintos diálogos de diferente manera. En el Protágoras, el arte de medir muestra el verdadero valor de los placeres, dolores y temores que se presentan ante nosotros y hace que las apariencias pierdan su poder, de modo que proporciona 'la paz firmemente enraizada en la verdad' y salva nuestra vida de la inestabilidad emocional, en cuanto nos libra del error y del consiguiente arrepentimiento (356 $\mathrm{d}$-e). El arte de medir es considerado como una cierta aritmética del exceso y el defecto (357 a-b) y la moderación parece depender del juicio de este arte.

En el Crátilo (411 e) Platón se plantea la relación inversa: la sabiduría depende de la moderación. Así, probablemente inventa una etimología para presentar la $\sigma \omega \varphi \rho \sigma^{\prime} v \eta$ como $\sigma \omega \tau \eta \rho i ́ \alpha ~ \varphi \rho o v \eta ́ \sigma \varepsilon \omega \varsigma$, i.e. como 'salvación de la sabiduría'. Con esta etimología parece que considera a la moderación como aquella virtud que mantiene a la sabiduría sana y salva en su puesto de mando, en el sentido de que sólo contando con un cierto poder para el control de los placeres excesivos o banales, puede la sabiduría gobernar y prescribir con determinación y soltura el cumplimiento de la acción recta.

Lo mismo encontramos en el Fedón (68 c 8-12) donde la moderación ante los placeres excesivos del cuerpo es propia del filósofo que tiene como meta la actividad intelectual, por lo que sujeta al cuerpo para que no se agrande en sus deseos y llene su vida de requerimientos triviales.

En la República (430d-432b; 433 c) Platón define la moderación como una cierta armonía o acuerdo sobre quién debe gobernar. Se trata de una virtud que no está restringida a una sola parte del alma o a una sola clase social de la ciudad, sino que todas las partes o clases deben poseerla. Es necesario que cada parte o clase realice su función específica sin extralimitarse, a fin de que la parte o clase superior pueda gobernar al conjunto, teniendo como meta el bien común. En cambio, cuando cualquiera de las partes pretende usurpar las funciones o atribuciones de las otras, se produce un conflicto interno o guerra civil.

\section{La relación entre $\sigma \omega \varphi \rho \sigma_{v} \eta$ y conocimiento en el Cármides}

La relación entre la moderación (o la sensatez) y la sabiduría (o el conocimiento) es muy estrecha en nuestro diálogo. La moderación se relaciona aquí con el conocimiento de lo que uno sabe e ignora, y con una cierta buena praxis. Sólo 
si uno sabe lo que sabe y lo que ignora, i.e. si conoce sus límites, puede emprender la búsqueda de lo que es el bien ${ }^{3}$, i.e. de la medida que la situación requiere.

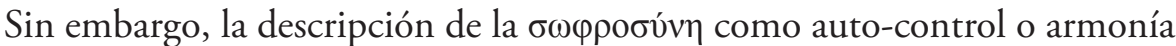
del alma es omitida en la segunda parte del diálogo, que está más bien dedicada a una discusión aparentemente 'estéril' sobre esta virtud, que parece ignorar los elementos más bajos o menos racionales del alma. Ante esta situación, algunos autores creen que Sócrates adopta una actitud hiper-intelectualista que ignora cualquier elemento no-cognitivo ${ }^{4}$. A mi modo de ver la acción dramática no ignora esos elementos sino que precisamente los tiene tan en cuenta que por ello mismo pone todo el énfasis en el conocimiento de uno mismo. ¿No es acaso el excesivo deseo de buena reputación, honor y gloria lo que obnubila la capacidad de adquirir esta virtud por parte de Cármides y de Critias? Sólo cuando la razón se aplica a buscar la verdad y a dejar que se manifieste la ignorancia del interlocutor al verse refutado, el ánimo de sobresalir del interlocutor puede empezar a moderarse. Esto es lo que sucede exactamente al final del diálogo. Cuando

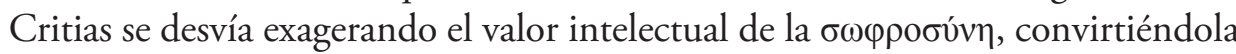
en una consciencia vacía de 'saber de los saberes y de sí misma', conforme con su arrogancia ${ }^{5}$, Sócrates somete a examen esta definición y acaba por rechazarla de plano. Uno puede creer que el diálogo acaba en aporía. Sin embargo, al volver la vista atrás, descubrimos que esta virtud queda definida, tanto en la acción dramática como en el plano teórico, como consciencia de los propios límites. La virtud de la moderación no puede ignorar la medida. Un hombre no puede pretender ocupar el puesto del sabio en sentido absoluto porque el saber humano es parcial, incompleto, susceptible de falsedad y limitado. Por el contrario, un

\footnotetext{
${ }^{3}$ También para Touzzo (2014) 280 la elaborada discusión de las varias formulaciones del auto-conocimiento ha de ponerse en relación con la 'bastante opaca' noción del conocimiento del bien y del mal.

${ }^{4}$ Stalley (2000) 267 al tratar esta cuestión refiere a Irwin (1977) 88 y a Kahn (1997) 188 n.8. También puede verse Irwin (1995) 39-41. Stalley observa que, dado que deseos y apetitos pueden corromper nuestro juicio sobre lo que deseamos realmente, el auténtico conocimiento de uno mismo requiere el auto-dominio (274). Ańade que saber lo que es bueno no consiste en tener información (275) sino en saber lo que uno realmente quiere. Este auto-conocimiento se logra a través del auto-examen (276). A mi modo de ver, lo interesante de este diálogo que que cuando no hay moderación en los placeres ni verdadero auto-conocimiento, es el examen socrático el que puede iniciar el proceso de cambio de actitud, como al final del Cármides sucede al propio Critias.

${ }^{5}$ Notomi (2000) 249: la virtud como autoconocimiento en Critias no puede ser un principio para el buen gobierno sino que es mera vanidad.
} 
hombre puede aspirar a cierta sabiduría en sentido relativo si conoce los límites de su saber, i.e. sabe lo que sabe y lo que ignora.

Esta consciencia de sus límites es precisamente lo que permite al sabio todos los demás movimientos de imposición de límites o medida en cada uno de sus actos en relación consigo mismo, con los otros y con los dioses. La continuidad de tales actos constituye una vida excelente porque derivan de una vida examinada. En este sentido se comprende que la moderación es la virtud por excelencia porque es la virtud que 'nace' de la comprensión de lo que uno es y de lo que las cosas son. A propósito de esta cuestión pregunta Sócrates: ' ¿Y no es un bien común para casi todos los hombres el que se nos haga transparente cada uno de

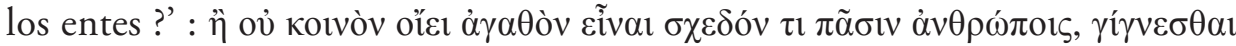

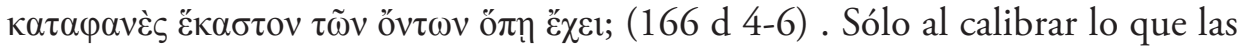
cosas, las personas y los dioses son, podemos actuar conforme con ellos. La acción moderada o medida resulta buena porque se ajusta a lo que es ${ }^{6}$.

Al comienzo del diálogo, Cármides ofrece tres posibles respuestas a la pregun-

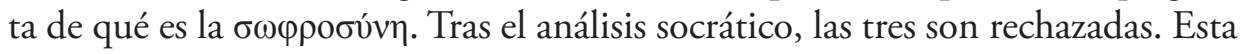
virtud no puede consistir en una cierta 'parsimonia' o 'lentitud' (actitud propia de la clase alta), ni en una cierta 'vergüenza' o 'pudor' (de origen socio-cultural), ni tampoco es un simple 'ocuparse cada uno de lo suyo' sin más. Sin embargo, en esta tercera respuesta se podría adivinar ya, en forma implícita, la noción clave de 'límite' si 'hacer lo propio' se interpreta como 'no entrometerse en lo ajeno, respetando las funciones y obras de los otros'.

Cuando Sócrates pone demasiada presión sobre Cármides con sus objeciones y contra-argumentos, éste le pasa la posta a Critias, quien retoma la noción presentada por Cármides (en 161 b) y define la moderación como 'hacer lo propio' (163 a). Sin embargo, puesto que hay artesanos que 'hacen lo ajeno' (producen para los demás) y aún así son moderados, su definición es refutable ${ }^{7}$

\footnotetext{
${ }^{6}$ Esta tesis se manifiesta también, aunque explicitada de otro modo, en la fórmula que identifica la virtud con la sabiduría en el Protágoras. Con relación a la moderación, dice Sócrates en este diálogo que el ser 'menos' que uno mismo, el ser incapaz de controlarse, es ignorancia,

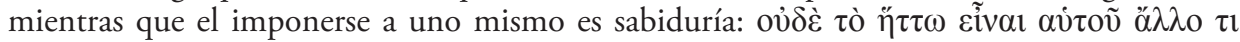

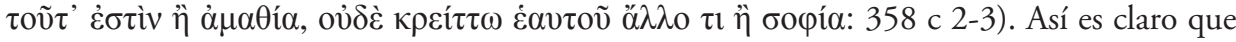
para poder ser virtuoso en el sentido de 'moderado' es preciso saber, es preciso ser sabio, poseer cierta sabiduría acerca de uno mismo y de cuáles son los placeres auténticos de la vida.

${ }^{7}$ Brennan entiende que Critias cae en contradicción, a pesar de su distinción entre poiein (hacer en general) y prattein (hacer lo noble). (2012).
} 
y él lo sabe. Intenta sin éxito salvar su definición estableciendo una distinción entre poiein (hacer en general) y prattein (hacer lo noble: to kalón). La cuestión del buen obrar parece requerir el conocimiento de lo que es el bien en cada caso y de cierto conocimiento de sí.

Esta cuestión del autoconocimiento resulta problemática para Sócrates, quien manifiesta que hay una cuestión que lo asombra. Se pregunta si los hombres moderados (o sensatos) ignoran o no que son moderados o sensatos (164 a 2-3).

Critias responde que en general ser moderado o sensato es lo mismo que el

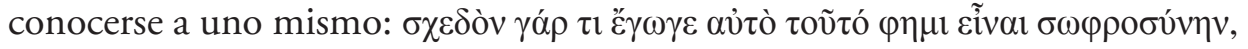

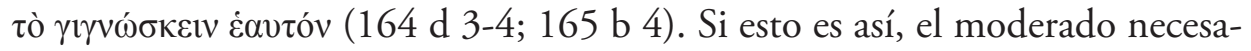
riamente se conoce a sí mismo y si se conoce, ha de saber que es moderado.

Por su parte, Sócrates afirma que él no sabe aquello que indaga y sólo una vez que lo haya examinado, será cuando esté dispuesto a decir si está o no de acuerdo con Critias (165 b 5-c 2) ${ }^{8}$. Los reparos de Sócrates pretenden poner límite a los intentos apresurados y exageradamente simplistas por parte de Critias. Sócrates está continuamente investigando lo que se le pone delante, no por refutar a Critias, dice, sino por temor a creer que sabe algo sin saberlo $(166 \text { c } 7-\mathrm{d} 2)^{9}$.

El hecho de que Sócrates siempre sospecha que podría no saber lo que cree saber es, para el lector, un indicio de que el que es verdaderamente moderado o sensato no sabe que lo es, sino que siempre piensa que aún no es lo suficientemente sensato, moderado o sabio, contrariamente a lo que afirma Critias. De hecho, en los diálogos platónicos, Sócrates nunca admite ser sabio ni virtuoso sino que son los otros los que así lo consideran, como es el caso del elogio de Sócrates por parte de Alcibíades en el Banquete.

La paradoja consiste en que para poder saber que uno no sabe algo, es necesario saber algo acerca de lo que uno no sabe. En este punto es interesante

\footnotetext{
${ }^{8}$ Los pasajes citados del Cármides siguen mayormente la traducción de Lledó (Gredos), con algunas modificaciones.

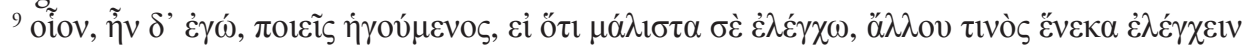

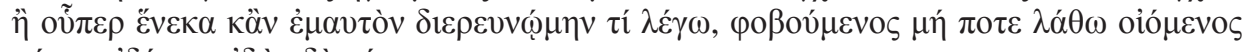

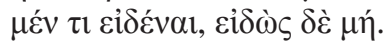


tener en cuenta un pasaje del Menón (80 e) en el cual Sócrates llama 'erístico' al argumento según el cual no le es posible a nadie buscar ni lo que sabe ni lo que no sabe: no podría buscar lo que sabe porque si ya lo sabe no necesita investigarlo, ni tampoco podría buscar lo que no sabe porque si no lo sabe, no podría saber lo que ha de buscar. Ciertamente, el que investiga sabe y no sabe lo que busca. De modo que 'saber' y 'no saber' no se deben tomar en sentido absoluto, sino relativamente a distintos contenidos y aspectos de la búsqueda. En el Menón Sócrates introduce la doctrina del aprendizaje como reminiscencia, según la cual el alma todo lo conoce, porque es inmortal y ha vivido muchas vidas (81c) y ańade que nada impide que quien recuerde una sola cosa, encuentre él mismo todas las demás, 'si es valeroso e infatigable en la búsqueda', por lo que no debe dejarse persuadir por el argumento erístico que lo volvería indolente y débil, sino por la doctrina de la reminiscencia 'que nos hace laboriosos e indagadores' (81 d-e).

Volviendo al Cármides, aunque esta solución de la reminiscencia es ajena a nuestro diálogo, el pasaje nos sirve para darnos cuenta de que Sócrates no se dejará atrapar por la erística ni tampoco por la pretensión arrogante de Critias. Que la moderación suponga el autoconocimiento no significa que el moderado se jacta de ser sabio y virtuoso, sino todo lo contrario: el autoconocimiento de lo que sabe y de lo que ignora lo vuelve cauteloso y humilde.

En su estrategia contra toda jactanciosa arrogancia, Sócrates, partiendo del

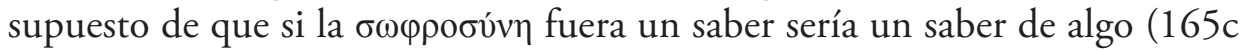
5-6), insiste en preguntar a Critias cuál es su objeto y su utilidad (166 b 5-6).

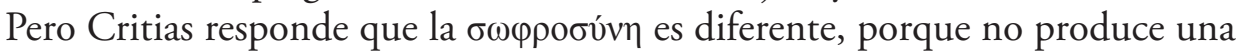
obra como la medicina produce la salud o la arquitectura, la casa, sino que es más bien como el cálculo o la geometría. Entonces Sócrates le recuerda que los objetos de estas últimas ciencias son distintos de las ciencias mismas. Critias replica que, mientras todos los otros saberes son de algo pero no de sí mismos, la $\sigma \omega \varphi \rho о \sigma v ́ v \eta$ es la única que además de ser un saber de todos los otros, lo

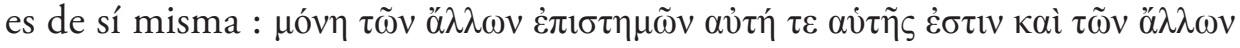
$\dot{\varepsilon} \pi \iota \sigma \tau \mu \tilde{\omega} \nu \dot{\varepsilon} \pi \iota \tau \tau \dot{\mu \eta}(166$ e 5-6 ; 166 c 2-3).

Sin advertencia alguna para el lector, el personaje Critias pasa de definir la

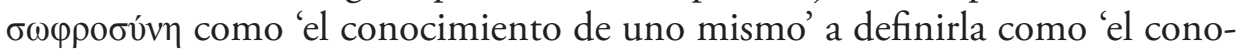
cimiento de las otras ciencias y de sí misma’. No se ofrece ninguna explicación ni justificación. El lector sospecha que Critias no necesita justificar el salto porque en realidad él se considera a sí mismo el moderado que lo sabe todo. 
Así, conocerse a sí mismo es saberse sabio en todo, a condición de no especificar nada. Pero como veremos, Sócrates buscará el modo de invalidar este paso,

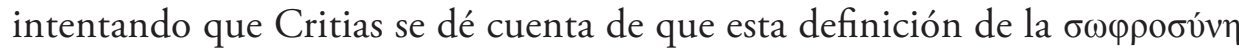
como conocimiento del conocimiento es imposible. Por eso le pregunta si,

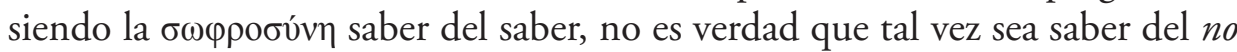

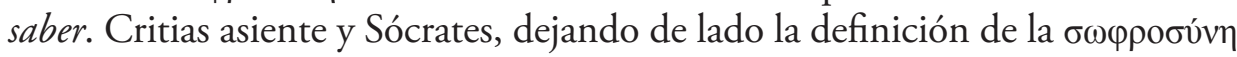
como ciencia de las ciencias que se autoconoce, la retoma como conocimiento de uno mismo:

En efecto, sólo el sensato se conocerá a sí mismo y será capaz de discernir realmente lo que sabe y lo que no sabe, y de la misma manera podrá investigar qué es lo que cada uno de los otros sabe y cree saber cuando sabe algo, y además qué es lo que cree saber y no sabe. Porque no habrá ningún otro que pueda saberlo $^{10}(167$ a $1-5)$.

Critias vuelve a asentir como si esta investigación de lo que no sabe el otro, no fuera con él, como si Sócrates no estuviera diciéndole que su definición de moderación o sensatez como 'ciencia de las ciencias sin objeto particular' es una quimera imposible porque toda ciencia es referencial y limitada a un campo.

\section{La aporía : Parménides tras el telón}

Para persuadir a Critias, Sócrates tiene que investigar si es posible este saber de lo que se sabe y de lo que no se sabe. Dice que se encuentra en una

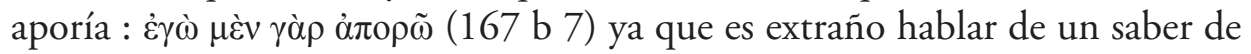
sí mismo y de los demás saberes, que a la par lo es de la ignorancia o de lo que no sabe, teniendo en cuenta que las demás operaciones sensibles y psíquicas tienen siempre un objeto de su operación. ¿¿Se puede afirmar un saber que no es de conocimiento alguno sino de sí mismo y de los otros? ${ }^{11}$

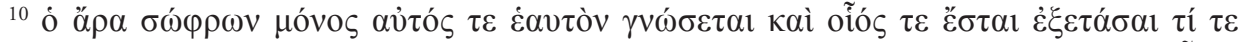

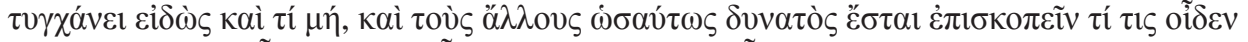

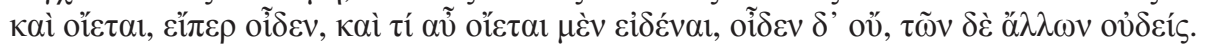

${ }^{11}$ Halper (2000) 316 comenta que para que haya conocimiento de conocimiento es necesario que sea distinto de las facultades sensibles y materiales y que Critias no puede comprenderlo porque no es capaz de separar lo inteligible de lo sensible.
} 
Sócrates insiste en que ese saber de sí y de las otras ciencias es saber de algo, se refiere a algo. Para que pueda ser de sí mismo debe tener algún contenido. $Y$ se encuentra tan perplejo que afirma :

Necesitamos un gran hombre ${ }^{12}$, mi amigo, que pudiera hacer una adecuada división sobre este punto con relación a todos los casos, determinando si ninguna cosa puede, por naturaleza, aplicar su propio poder a sí misma, sino solamente a otras cosas, o si algunas pueden pero otras no. Y también necesitamos que determine si, habiendo algunas que se aplican a sí mismas, el conocimiento ( $\dot{\varepsilon} \pi \sigma \tau \eta \dot{\mu \eta})$

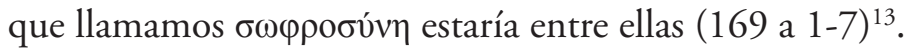

A mi juicio, ese gran hombre al que tal vez Platón esté echando de menos podría ser Parménides. Para empezar el modo de expresarse de Sócrates con la referencia a 'las cosas que son' ( $\tau \tilde{\omega} v$ öv $\tau \omega v)$ evoca directamente a Parménides. Que Parménides podría estar apostado detrás del telón de la escena del Cármides, también nos lo indican otros dos pasajes de tono ontológico : por una parte, el pasaje citado de 166 d 2-6 donde se menciona la expresión

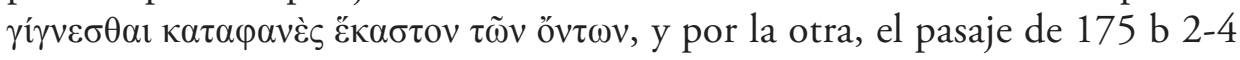
donde Sócrates dice que han sido completamente derrotados y son incapaces

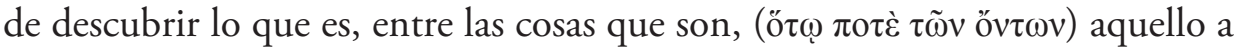
lo que el legislador le dio el nombre de $\sigma \omega \varphi \rho \sigma^{\prime} v$ m. En segundo lugar, la introducción del verbo 'dividir'también nos remite a él. ¿Quién sino Parménides ha establecido la más grande, definitiva y tajante división posible (entre lo que es y lo que no es)?

Pero lo más importante con relación a nuestro pasaje es que ha sido Parménides quien ha hecho, por primera vez en la historia del pensamiento occidental, una reflexión sobre el conocimiento mismo, revelando, la necesaria sujeción del aprehender noético respecto de lo que es, tal como se afirma en el fragmento 3 de su Poema (aunque se trata de una línea incompleta cuya ubicación e interpretación siguen siendo muy controvertidas; la historia de la interpretación de este fragmento ha dado lugar a traducciones diversas según

\footnotetext{
${ }^{12}$ Hay un pasaje paralelo en el que también se 'necesitaría un hombre de gran talento' para resolver el problema de las propiedades reflexivas (Parménides 135 a).

${ }^{13}$ En este caso sigo la traducción de R. Kent Sprague en J. Cooper and D. Hutchinson

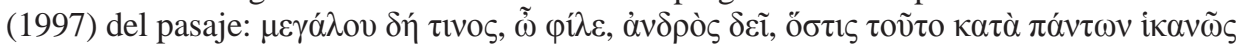

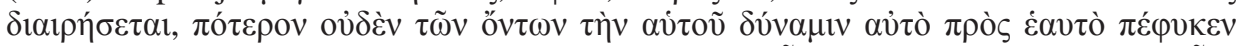

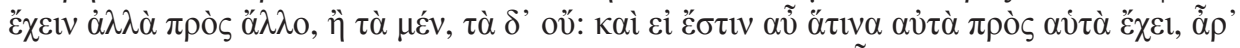

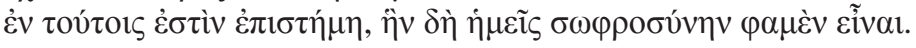


sea la base filológica que se asuma $\left.{ }^{14}\right)$. A la luz de nuestro pasaje, este fragmento apunta a la necesaria referencia del conocimiento hacia algo otro diferente de sí mismo.

Por otra parte, ha sido Parménides quien ha establecido una división entre el conocimiento seguro y persuasivo, y otro tipo de aseveración que resulta dudoso o engañoso. Para poder establecer esa distinción radical, Parménides ha debido ejercer el poder del conocimiento de auto-examinarse a sí mismo, al que se refiere aquí Sócrates. En efecto, Parménides ha descubierto el modo peculiar de ser del aprehender noético como conocimiento seguro y confiable, en cuanto se sabe capaz de ofrecer una prueba 'argumentada y bien redonda' de lo que es. Al contrario, la opinión engañosa cree que ser y no ser son y no son lo mismo (B6.4-9). Según Parménides, ser consciente de la diferencia entre el estatuto epistemológico de las opiniones y el de los conocimientos sólo parece ser posible gracias a la capacidad de seguir la prueba racional revelada por la diosa. Si esto es así, la opinión podría referirse a otra cosa pero no podría realmente referirse a sí misma, en el sentido de ser capaz de juzgar su grado de verdad, sino que hace falta una capacidad superior a ella para descubrir su engaño. De modo que Parménides podría ser el hombre capaz de distinguir las potencias que pueden solamente referirse a un objeto 'externo' por así decir, de las que pueden considerar al propio sujeto y realizar un juicio crítico sobre las capacidades desiguales que este posee. Sin duda Parménides ha sido uno de los primeros que ha establecido esta diferencia entre la potencia que se autoconoce como segura y la que es descubierta como autoengañosa, aunque

\footnotetext{
${ }^{14}$ Puede traducirse como: 'For the same thing can be thought as can be' (Kirk-Raven, 1957); 'For the same thing can be thought and can exist' (Tarán, 1965); 'Because the same thing is there for thinking and for being' (Gallop, 1984); 'For the same thing is there both to be thought of and to be' (Schofield in Kirk-Raven-Schofield, 1986); 'C'est en effet une suele et mème chose que l'on pense et qui est' (Frère 1987): 'For there is the same thing for thought and for being' (O’Brien, 1987). Según esta última versión auto es el sujeto de einai y el objeto directo de noein. En tal sentido, o bien el fragmento se relaciona con B2.8 (Gallop18) o con B6.1 (O’Brien) para significar que es imposible 'pensar' sin 'pensar lo que es'. Si el fragmento significa que pensar reuiere un objeto real esto no implica que los objetos ficticios como los unicornios sean reales porque pueden ser pensados con la imaginación. Por el contrario, noein significa 'coger o captar' lo que indica que es una clase de operación intencional que captura un contenido como 'siendo'. Algunos investigadores enfatizan el significado epistemológico: 'For ascertaining and being real are one and the same' (Robinson, 1975) en el sentido de que cuando uno capta algo uno está obligado a captarlo como siendo algo de algún modo. Otros intérpretes como Vlastos (1953), asumen una identificación: 'Thinking and Being are the same thing' (Cf. Bossi, 2015, 27-28).
} 
también Heráclito parece preocupado por establecer esta distinción ${ }^{15}$. Y es evidente que la diferencia entre ciencia o conocimiento seguro, por una parte, y opinión susceptible de verdad o falsedad, por la otra, es una de las herencias parmenídeas más importantes recibidas por Platón. Aunque Parménides no

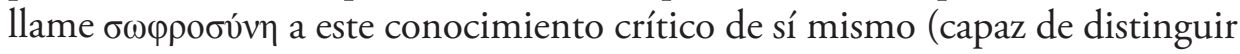
la persuasión firme y probada, respecto de la opinión engañosa) si tenemos en

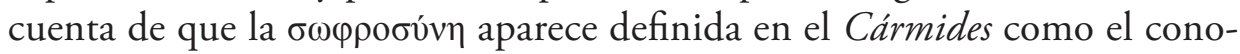
cimiento de lo que uno sabe e ignora, la sospecha de que Platón podría estar pensando en Parménides no carece de cierto fundamento.

Por otra parte, el principio de la 'necesaria referencia hacia algo que es' es la piedra angular sobre la que Sócrates construye su refutación de Critias acerca de la $\sigma \omega \varphi \rho o \sigma u ́ v \eta$. Y sin embargo, Sócrates intentará violar el principio parmenídeo a fin de mostrar a Critias, por el absurdo, que esto no es posible. Ante un Critias 'contagiado de su propia incertidumbre y vencido por la aporía', Sócrates decide concederle, como hipótesis provisional, que es posible un saber del saber que no tenga contenido u objeto alguno, para poder continuar con la investigación (169 d).

La comicidad de la escena no puede pasarnos desapercibida. Por una parte, hay una fuerte crítica velada a la persona de Critias, que parece carecer de juicio crítico, pace su nombre. Critias cree que si alguien tuviera ese saber se conocería a sí mismo como poseedor de tal conocimiento (169 e). Es evidente que Platón desea presentar a Critias especialmente preocupado por enfatizar la cuestión de quien lo tendría, dando a entender que él mismo se cree poseedor de él. Pero la comicidad se manifiesta en la contradicción entre esta pretensión velada de Critias y su situación dramática, a saber, que está bloqueado por la aporía. (Por lo demás, como ya hemos señalado, el hecho de que tanto Sócrates como Critias experimentan una aporía es una prueba irrefutable de que existe un saber del no saber).

Sócrates vuelve a la carga con la misma pregunta de si al que posee el conocimiento de este saber y se conoce a sí mismo no le viene necesariamente el discernir las cosas que sabe y las que no. Critias le contesta que ambas cosas 'son uno y lo mismo'. Podemos suponer que, desde el punto de vista de Critias, el que posee el saber del saber lo sabe todo, y esto es lo mismo que saber que nada

${ }^{15}$ Me he ocupado de establecer una comparación entre ambos filósofos con relación a este asunto en Bossi (2015). 
ignora. Sócrates le contesta que tal vez sea así. Pero su respuesta, interpreto, proviene de su propia concepción del saber, como algo parcial y referencial : saber lo que uno sabe es saber algo determinado, y por eso, en cierto modo, es lo mismo que saber que uno no lo sabe todo o saber que ignora. Sócrates agrega que él sigue siendo el mismo, porque sigue sin aprender cómo es que es igual el saber las cosas que uno sabe y el saber las que no sabe (169 e-170 a).

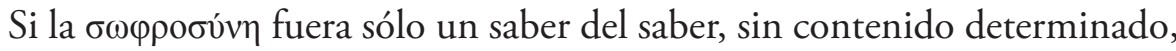
el que lo posea no sabría qué es lo que sabe, sino (aparentemente) solamente que sabe $(170 \mathrm{c})$. Tal es la situación dramática de Critias. Sócrates quiere demostrarle que se engaña: sin contenido no hay saber y sin saber no puede haber 'consciencia de saber' real, sino solamente autoengańo, fruto de la arrogancia. Para ello da un largo rodeo muy cauteloso.

Un saber vacuo no será útil, le dice, porque no será capaz de indagar si los otros saben o no $(171 \mathrm{~d})$. En cambio, prosigue Sócrates, si la $\sigma \omega \varphi \rho \circ \sigma u ́ v \eta$ fuese el conocimiento de lo que uno sabe e ignora y de lo que los otros saben e ignoran sería muy provechosa porque entregaríamos a los expertos los asuntos que ignoramos, asignaríamos funciones a los subordinados en función de sus conocimientos y, desechado el error, los hombres obrarían bien y serían felices. Sócrates concluye que, por el contrario, buscando un saber mayor de lo que en realidad es, han estado buscando una cosa 'inútil' (171 e-172 d). En ningún lugar se encuentra un saber en tales condiciones (172 a). Este sueńo de un saber total y absoluto es inalcanzable (173 d). Y no sólo eso, aunque cada uno supiera perfectamente de lo suyo, (el médico sobre la salud, el zapatero sobre los zapatos) no es ese tipo de conocimiento el que hace felices a los hombres sino el conocimiento del bien y del mal, el cual hace que todas las demás ciencias y artes sean buenas y provechosas (174 b-d). Una ciudad eficiente en la que cada uno hace bien su trabajo no es necesariamente una ciudad feliz. La $\sigma \omega \varphi р о б v ́ v \eta$ definida por Critias no es útil ni provechosa porque no se refiere a ningún campo de objetos determinado; Sócrates había comenzado a tener miedo de que nada útil sacarían con ello y ahora se da cuenta de que por este camino han sido derrotados en toda la línea (175 b):

Y el caso es que nos hemos puesto de acuerdo en muchas cosas que no se corresponden en el logos. Nos pusimos de acuerdo en que había un saber del saber, no permitiéndolo el logos. Y nos pusimos de acuerdo en que, con ayuda de esta ciencia, podíamos conocer las obras de todas las otras -cosa que tampoco permite el logos- a fin de que el sensato viniera a ser conocedor de las que sabe 
porque las sabe, y de las que no sabe porque no las sabe. Todo esto pues lo hemos concedido con excesiva generosidad, pasando por alto lo imposible que es que las que uno no sabe de ninguna manera, las sepa, sin embargo, de algún modo. Porque nuestro acuerdo viene a decir que se saben aquellas cosas que no se saben, aunque yo creo que no podría haber nada más irracional que esto. Y sin embargo, siendo nuestra pesquisa tan de buenos modales y tan poco dura, no por ello ha podido encontrar mejor la verdad, sino que de tal manera <el lógos $>$ se ha reído de ella...(175 b 4-d 2) ${ }^{16}$.

El pasaje es controvertido y difícil de comprender si no se asumen ciertos supuestos interpretativos ${ }^{17}$. A mi modo de ver, el logos de este pasaje debe ser interpretado como el pensar y el hablar en general, y lo que no pueden conceder (ni el logos ni Sócrates) ahora de ninguna manera es que haya autoconciencia de tener conocimiento de todas las ciencias. El conocimiento de todas las ciencias sería divino si lo hubiera, no humano. Todo lo que permite el logos es un conocimiento parcial, referido a algo que es. De ese conocimiento parcial de algo que es, sí puede haber, naturalmente, autoconciencia ${ }^{18}$. Es la autoconciencia que tiene Sócrates en la Apología de lo que sabe y de lo que ignora.

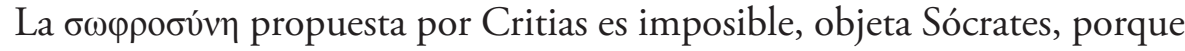
es imposible que lo que no se sabe en absoluto pueda saberse de algún modo

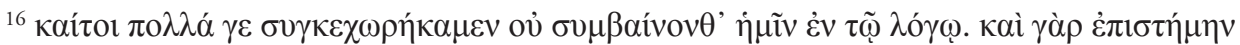

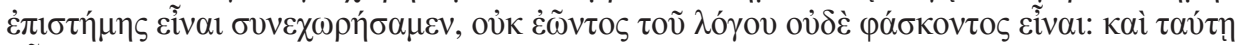

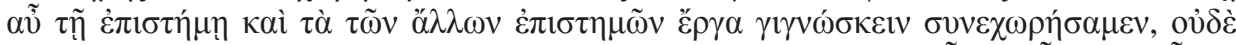

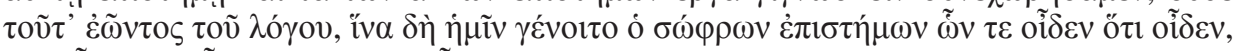

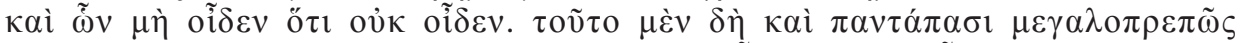

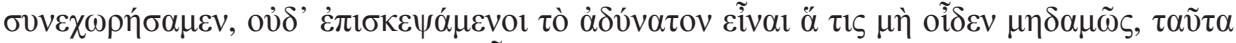

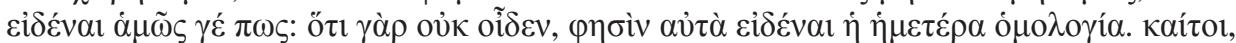

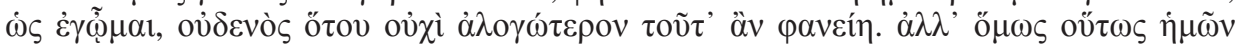

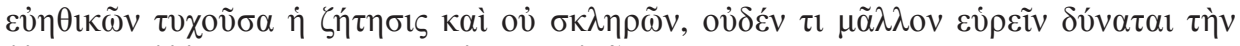

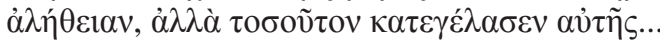

${ }^{17}$ Tuozzo (2014) 290-3 observa que es una exageración de parte de Sócrates negar la posibilidad de un conocimiento reflexivo, cuando esto no se niega en el argumento anterior, sino

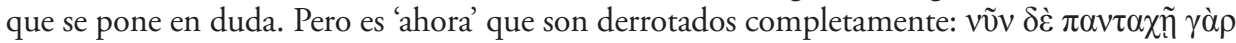
$\dot{\eta} \tau \tau \omega ́ \mu \varepsilon \theta \alpha$ (175 b 2-3). Las formas verbales que corresponden al logos no indican pasado: o

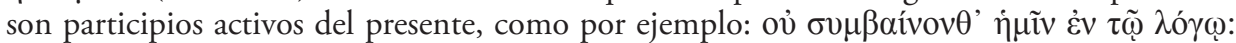
'que no se corresponden para nosotros en el lógos' (175 b 5); o genitivos absolutos, como en

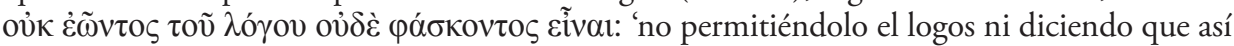

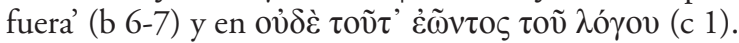

${ }^{18}$ También Stalley (2000) 257 parece darse cuenta de que no se está examinando al argumento anterior cuando dice que ahora es el logos lo que debe ser sujeto al elenchos.
} 


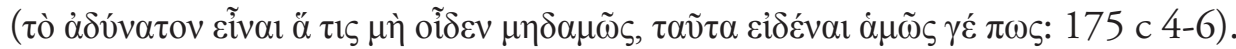
No saber en absoluto es no tener conocimiento relativo a ningún objeto y saber de algún modo es saber algo relativamente a un objeto. No saber nada es no saber. Saber es siempre saber algo. A Sócrates le parece que nada es 'más

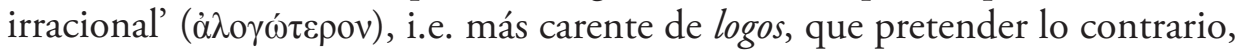
porque el logos está necesariamente referido a algo que es. E inversamente, sin conocimiento relativo a un contenido u objeto, sin conocimiento de primer orden (saber $\mathrm{x}$ ) no puede haber conocimiento relativo a este conocimiento, i.e. conocimiento de segundo orden (saber que uno sabe $\mathrm{x}$ ).

La investigación se ha reído de la verdad y ha procedido en forma 'comple-

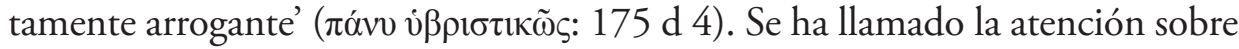
esta expresión, de cuya ironía Sócrates parece que es plenamente consciente, ya

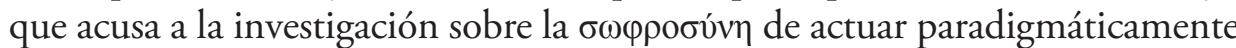
sin $\sigma \omega \varphi \rho о \sigma u ́ v \eta$, con una violencia arrogante ${ }^{19}$.

Lo que está debajo de las palabras de Sócrates es la situación dramática. Para decirlo brevemente: si Critias cree que tiene este conocimiento absoluto, cree que lo sabe todo, y por tanto, cree que no ignora nada. Pero, Sócrates objeta, nadie puede saber que no ignora nada, porque es imposible que 'lo que no se sabe en absoluto' (i.e. 'nada ignoro') 'pueda saberse de algún modo' (i.e. 'sé que nada ignoro').

En sentido fuerte, parmenídeo, lo que no se sabe en absoluto, lo que no es captable en absoluto no es, y por eso no puede saberse en absoluto, ni mucho menos 'de algún modo'. De modo que para ser consciente de la propia ignorancia es necesario tener un mínimo conocimiento de aquello que no se sabe. El conocimiento, incluso de la propia ignorancia, se define por referencia a un asunto que es.

Por otra parte, afirmar que es imposible 'saber de algún modo' lo que uno 'no sabe en absoluto' no niega que uno pueda saber 'de algún modo' que no sabe 'algo determinado', como es el caso de Sócrates cuando dice que no sabe, que duda, que no ve 'salida' para la propuesta de una moderación/sensatez sin obra ni utilidad, entendida como 'conciencia de conocimiento absoluto

\footnotetext{
19 Tuozzo (2014) 290.
} 
y de absolutamente ninguna ignorancia', i.e. eso que Critias dice que es la

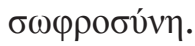

\section{La euporía implícita: una última oportunidad para Cármides y Critias}

Sócrates lamenta este desenlace por Cármides, porque siendo él 'tan bello de cuerpo y muy sensato ( $\sigma \omega \varphi \rho o v \varepsilon ́ \sigma \tau \alpha \tau o \varsigma)$ en su alma, no sacará provecho ni

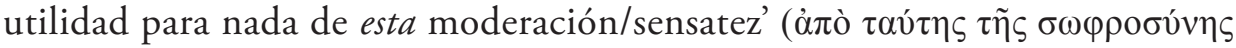
175 e 1). Esta sensatez es la que Critias define como saber absoluto de saberes, la que el logos (léase Sócrates) ha mostrado como pura jactancia de vacío que se burla de la verdad.

A pesar de su insistencia en preguntar tantas veces por el objeto, para salvar a

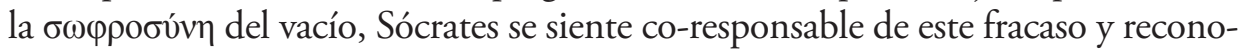
ce que no han llegado a buen puerto con tan buenos modales ni con tantas concesiones. Sócrates ha sido tan 'políticamente correcto', que no ha podido ayudar a Critias a dar a luz. Pero es que Critias, de tan lleno de sí mismo, está vacío ${ }^{20}$.

Sócrates añade que lo irrita más el ensalmo, el encantamiento que aprendió del tracio, y que después de tanto esfuerzo, descubre ahora como algo baladí (175 e 2-5). No habiendo podido hacer parir a Critias, Sócrates imagina que Cármides no ha podido aprender nada del diálogo. Y sin embargo, inmediatamente se retracta y afirma que no cree que la moderación/sensatez pueda ser algo negativo, sino que lo que pasa es que ha planteado mal su búsqueda, puesto que la

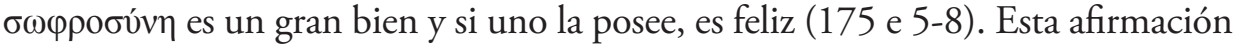

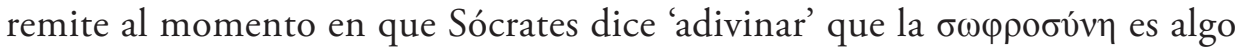
bueno y beneficioso (169 b 4-5). ¿Por qué ahora este giro?

Sócrates invita a Cármides a mirar a ver si tiene esta virtud y no precisa del ensalmo. El joven responde que no sabe si la tiene o no, que cómo podría saberlo cuando ellos no son capaces de saber en qué consiste (176 a 7-8).

${ }^{20}$ Schmid (1998) 148 señala que Critias debe de sentirse frustrado puesto que no puede reclamar para sí el conocimiento y la superioridad que él 'sabe' que tiene. Pero como veremos, Platón, al final, deja que Critias se humille y se salve. 


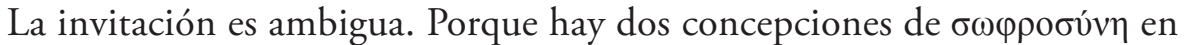
juego, la de Sócrates y la de Critias. Pero el joven no está plenamente convencido del supuesto fracaso porque seguramente sospecha que Sócrates sabe más de lo que muestra y se declara muy necesitado del ensalmo (176 b 1-4), tras el fracaso de su tutor delante de sus ojos. Platón quiere hacernos ver que el joven desea liberarse del vacío de Critias y aprender a adquirir esa otra $\sigma \omega \varphi \rho \circ \sigma v ́ v \eta$, la que Sócrates define como la consciencia de lo que se sabe y de lo que se ignora. Sócrates acaba de manifestarla en la acción dramática al admitir, por una parte, la supuesta derrota de su búsqueda y por la otra, la afirmación positiva de esta virtud. Sócrates tiene algún conocimiento de lo que es la $\sigma \omega \varphi \rho \sigma^{\prime} v \eta$, ya que él mismo la posee y por eso puede, en cierto modo, hacerla nacer en otros, por medio del diálogo refutativo. El joven se ha debido percatar de la parodia políticamente correcta de Sócrates, quien pretende hacerse co-responsable del fracaso como si él no hubiera sido el verdadero responsable de la refutación.

A pesar de todo, Sócrates ha defendido su concepción de $\sigma \omega \varphi \rho o \sigma v ́ v \eta$ tanto con la pregunta machaconamente insistente por el contenido, como con la aceptación de los límites de la indagación. Porque más allá de los buenos modales, Sócrates ha sido capaz de refutar a Critias. Pero 'el juego de roles' no acaba aquí.

Critias afirma que el hecho de que Cármides se someta al ensalmo socrático

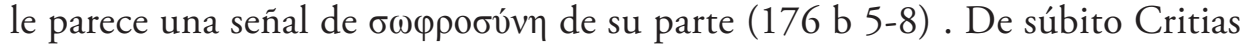

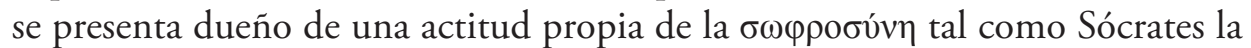
define. Al darse cuenta de que él no puede enseñar a su discípulo, se lo cede a su interlocutor. Critias ha hecho un ejercicio de $\sigma \omega \varphi \rho \sigma^{\prime} v \eta$ socrática en cuanto ha tomado consciencia de sus limitaciones docentes. Al final, este Critias ha sido capaz de abandonar sus pretensiones de grandeza, para aprender algo sobre sí mismo, una verdad que es punto de partida de un bien, para el joven y para sí mismo.

Parece que Platón no desea condenarlo irremediablemente a su arrogancia sino que al final desea redimirlo, mostrar que ha aprendido algo de la refutación. Esto indica que tiene un juicio de él un poco más elevado que el de Jenofonte, quien lo considera uno de los dirigentes más ladrones, violentos y asesinos, un hombre que no podía vivir con poco dinero ni controlar sus apetitos de poder, riquezas y sexo (Mem. 1.2.12; Hellenica $2.3 .12 ; 2.3 .16 ; 2.4 .1 ; 3.1 .4)^{21}$. Quizás

${ }^{21}$ Tuozzo $(2014,52-84)$ defiende una visión contraria a este juicio de Jenofonte, a quien le convenía demonizar a Critias para exculparse a sí mismo, que ha influido negativamente en 
Platón lo ve como un aristócrata idealista de buena voluntad que buscaba la justicia pero falló necesariamente porque no era consciente de su propia ignorancia ${ }^{22}$.

Ahora el joven siente gratitud. Y la expresa de la forma más suave posible para curar el orgullo herido de su maestro. Afirma que seguirá a Sócrates y que no se despegará de él porque sería indigno 'que no se dejase persuadir por su tutor y no hiciera lo que éste le manda' ( 176 b 9- c 2). Critias recupera la autoestima y le responde con valentía: 'En verdad, te lo mando'(176 c 3). Le ordena seguir a Sócrates, a su propio adversario. Una nueva muestra de humildad. De auténtica $\sigma \omega \varphi р о б u ́ v \eta$. Para finalizar, Sócrates se deja 'obligar' por el joven a continuar con su tratamiento a base de argumentos encantadores. Y éste insiste que ha de ser de este modo porque 'Critias así lo manda' (176 c 8-9).

Sócrates se queja: no le queda la posibilidad de deliberar ni de ser escuchado $^{23}$, porque cuando el joven pone manos a la obra y está listo a emplear la fuerza, no hay hombre que pueda oponerse (176 d 1-3). Sócrates puede resistir sus bellos encantos, pero no puede oponerse a su deseo de ser encantado por él ${ }^{24}$.

\section{Conclusión}

De este manera termina el diálogo, en clave de esperanza: la creencia socrática

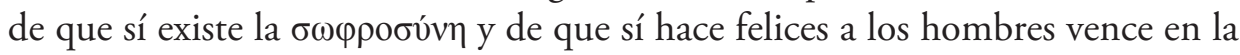

la interpretación del diálogo y entiende que no hay razón para pensar que Platón consideraba a Critias un vicioso o un sofista, porque no enseńaba retórica por dinero y nadie se refiere a él en esos términos en el siglo -IV. Era un poeta, un pensador y un teórico social. Al autor le parece que Platón lo eligió como interlocutor porque defendía la moderación como un ideal personal y cívico.

${ }_{22}^{2}$ Notomi (2000) 249.

${ }^{23}$ Quizás esta negación de permiso para pensárselo, y ser escuchado, y esta referencia a la fuerza y al mandato evocan, en el auditorio, el autoritarismo de los Treinta bajo el mando de Critias. En efecto, a los ciudadanos despojados de sus derechos no se les permitió defenderse en juicio y así muchos fueron condenados a muerte. Sin embargo, a mi modo de ver, la fuerte complicidad de esta escena final pone esta interpretación en duda. Para un análisis detallado de la cuestión, véase Tuozzo (2014) 300-303.

${ }^{24}$ Schmid (1998) 151 indica que el final es un reverso del principio: Cármides, quien encarna al joven bello y malcriado y Critias, el sofístico poeta tiránico se unen para forzar al filófoso a que les enseñe la virtud y el filósofo no puede oponerse, porque ellos son demasiado fuertes. 
acción dramática. Al final, Platón llama a escena a la gran esquiva $\sigma \omega \varphi \rho o \sigma v ́ v \eta$ alada, la viste de victoria, y la hace revolotear sobre las tres cabezas mortales.

Contra lo que pudiera parecer, tampoco el Cármides acaba en aporía. Y digo tampoco porque lo encuentro análogo al Lisis donde no se define lo que es la amistad pero al final del diálogo los personajes experimentan que a lo largo de su búsqueda en común se han hecho amigos ${ }^{25}$. Aquí sucede algo muy semejante. Aunque se ha rechazado la definición de Critias, se ha ofrecido una definición de

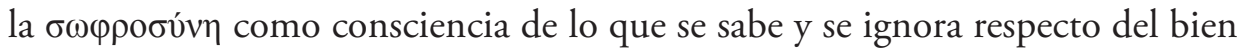
y el mal, que no es invalidada, y lo más importante quizás es que se acaba por mostrar en la acción dramática que los tres personajes centrales participan en alguna medida de la $\sigma \omega \varphi \rho о \sigma u ́ v \eta$, o quizás sea mejor decir, que han traspasado el umbral de una puerta que conduce a ella. Sócrates es consciente de sus fallos en la investigación pero a la vez siente que tiene algo que enseñar a Cármides ${ }^{26}$; el mismo Critias es capaz de realizar un acto de $\sigma \omega \varphi \rho \sigma^{\prime} v$ al ceder su alumno a Sócrates, y el joven Cármides, habiendo comprobado las limitaciones de Critias, se siente entusiasmado de seguir a Sócrates porque es consciente de que probablemente no posea esa virtud.

Por otra parte, no hay conocimiento de segundo orden sin conocimiento de primer orden, de modo que para que la refutación socrática sea capaz de indagar a los interlocutores y revelar su ignorancia, es necesario que el mismo Sócrates posea cierto conocimiento relevante de primer orden ${ }^{27}$. ¿Y qué es lo que sabe Sócrates? Entre otras cosas, que no puede haber saber sin estar referido a algo que es; que el bien es el objeto de este saber particular; que este saber no consiste en una mera eficacia técnica, ni en un cierto sentimiento de vergüenza inculcado por la sociedad o la cultura, y que la posesión de este saber nos hace felices. Y nos hace felices, sugiero, porque nos permite obrar bien en forma personal, imponiendo límites a la acción propia, a partir del conocimiento de uno mismo.

\footnotetext{
${ }^{25}$ Para una defensa de por qué el Lisis no termina en aporía, véase Bossi (2000).

${ }^{26}$ Stalley (2000) 258 observa que Sócrates es el que posee esta virtud porque ha sabido mantenerse calmo en la guerra, controlarse ante su deseo erótico, reconocer lo que sabe y lo que ignora, lo que otros saben e ignoran y lo que debe ser la naturaleza del bien y el mal. La paradoja es que posee la virtud aunque no posee la terminología precisa para ofrecer una explicación probatoria acerca de ella, y es precisamente una prueba de que posee la virtud el hecho de que sabe que no posee tal explicación.

${ }^{27}$ Como señala Kahn (1998) 201.
} 
A mi modo de ver Parménides proporciona la base teórica sobre la que se apoya el Cármides. El pensar se relaciona con lo que es, en una suerte de relación promisoria o contractual. B 834 contiene la doctrina que Sócrates conoce y defiende: No encontrarás el pensar desnudo o vacío de lo que es 'en lo cual está expresado'. El argumento de Critias pretendía reirse de la verdad pero el logos socrático acaba por encarnar el espíritu de la comedia al reírse de su incapacidad para ver sus propias limitaciones.

No es casualidad que el Cármides, serenamente, resista el paso de los tiem$\operatorname{pos}^{28}$.

\section{Bibliografía}

Aubenque, P. (2004). «Sócrates y la aporía ontológica» Azafea, Rev. Filos., 6, pp. 17-28.

Bossi, B. (2000). «Is the Lysis really aporetic?» in T. Robinson - L. Brisson, (eds.) Plato,

Euthydemus, Lysis Charmides, Proceedings of the V Symposium Platonicum Selected Papers, International Plato Studies, Vol. 13., Sankt Augustin, Academia Verlag, Germany, pp. 172-179.

(2015). "What Heraclitus and Parmenides have in Common on Reality and Deception», Logos. Anales del Seminario de Metafisica, Vol. 48, pp. 21-34.

Brennan, T. (2012) «The Implicit Refutation of Critias», Phrónesis, Vol. 57, No. 3, pp. 240-250.

GonzÁlez, F.J. (1995). «Self-Knowledge, Practical Knowledge, and Insight: Plato’s

Dialectic and the Dialogue Form» in Francisco J. Gonzalez (ed.) The Third Way:

New Directions in Platonic Studies. Lanham: Rowman \& Littlefield Publishers Inc., pp. 155-187.

Halper, E. (2000). «Is Knowledge of Knowledge Possible? Charmides 167a -169 d» in

T. Robinson - L. Brisson, (eds.) Plato, Euthydemus, Lysis Charmides, Proceedings of the V Symposium Platonicum Selected Papers, International Plato Studies, Vol. 13., Sankt Augustin, Academia Verlag, Germany, pp. 309-316.

Irwin, T. (1977). Plato's Moral Theory, Oxford.

(1995). Plato's Ethics, Oxford.

${ }^{28}$ Schmid (1998) 151. 
Kann, C. (1998). Plato and the Socratic Dialogue, The Philosophical Use of a Literary Form, CUP 1998.

Notomi, N. (2000). «Critias and the Origin of Plato's Political Philosophy» in T. Robinson - L. Brisson, (eds.) Plato, Euthydemus, Lysis Charmides, Proceedings of the V Symposium Platonicum Selected Papers, International Plato Studies, Vol. 13., Sankt Augustin, Academia Verlag, Germany, pp. 237-250.

Schmid, W.Th. (1998). Plato's Charmides and the Socratic Ideal of Rationality, SUNY.

Stalley, R. F. (2000). «Sophrosyne in the Charmides» in T. Robinson - L. Brisson, (eds.) Plato, Euthydemus, Lysis Charmides, Proceedings of the V Symposium Platonicum Selected Papers, International Plato Studies, Vol. 13., Sankt Augustin, Academia Verlag, Germany, pp. 265-277.

TARrant, H. (2000). «Naming Socratic Interrogation in the Charmides» in T. Robinson - L. Brisson, (eds.) Plato, Euthydemus, Lysis Charmides, Proceedings of the V Symposium Platonicum Selected Papers, International Plato Studies, Vol. 13., Sankt Augustin, Academia Verlag, Germany, pp. 251-258.

Tsouna, V. (1997). «Socrates' Attack on Intellectualism in the Charmides» in M. McPherran (ed.) New Essays in Socratic Studies: Wisdom, Ignorance and Virtue, Apeiron XXX 4, Dec. pp. 63-78.

Tuckey, T. G. (1951). Plato's Charmides, CUP.

Tuozzo, Th. (2014). Plato's Charmides, Positive Elenchus in a 'Socratic' Dialogue, CUP.

Enviado: 4/03/2016

Aceptado: 13/05/2016

\section{(9) $(\Theta \Theta$}

ENDOXA está bajo una licencia de Creative Commons Reconocimiento-NoComercial-SinObraDerivada 4.0 Internacional 